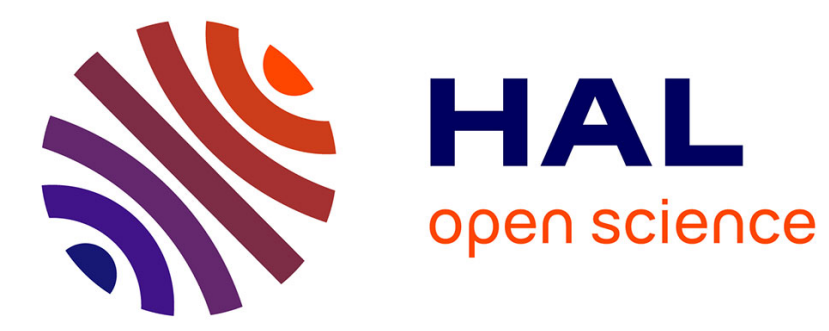

\title{
An immersion into a Multi-Agent Store Simulation
} Philippe Mathieu, David Panzoli, Sébastien Picault

\section{To cite this version:}

Philippe Mathieu, David Panzoli, Sébastien Picault. An immersion into a Multi-Agent Store Simulation. 10th International Conference on Practical Applications of Agents and Multi-Agent Systems (PAAMS'2012), Mar 2012, Salamanca, Spain. pp.273-276. hal-00826439

\section{HAL Id: hal-00826439 \\ https://hal.science/hal-00826439}

Submitted on 29 Oct 2013

HAL is a multi-disciplinary open access archive for the deposit and dissemination of scientific research documents, whether they are published or not. The documents may come from teaching and research institutions in France or abroad, or from public or private research centers.
L'archive ouverte pluridisciplinaire HAL, est destinée au dépôt et à la diffusion de documents scientifiques de niveau recherche, publiés ou non, émanant des établissements d'enseignement et de recherche français ou étrangers, des laboratoires publics ou privés. 


\title{
An Immersion into a Multi-Agent Store Simulation
}

\author{
Philippe MATHIEU, David PANZOLI and Sébastien PICAULT
}

\section{Introduction: an Interaction-Based Simulation}

FORMAT-STORE ${ }^{1}$ is a Serious Game (SG) in $3 \mathrm{~d}$ designed in collaboration with the game studio Idées-3 $\mathrm{Com}^{2}$ and the business school ENACO ${ }^{3}$, aimed at training undergraduate students to the management of a convenience store and customer relationship. In FORMAT-STORE, the learner is immersed in a virtual replica of a store populated by artificial customers, so as to practice daily activities of a salesperson. Immersive SG raise specific issues as explained in [3]. An Interaction-Oriented approach such as IODA [2] offers a particularly convenient way to address the multiple problems of such a SG simultaneously.

Basically, the IODA approach is based upon three key ideas [2]: 1) each relevant entity should be represented by an agent, 2) each behavior should be written as an abstract interaction, which is roughly a condition/action rule that can occur between a source agent (which performs the interaction) and a target agent (which undergoes it), and 3) the simulation model is described by the assignation of interactions to source and target agent families, which is achieved inside the interaction matrix (cf. fig. 1). This allows for a generic (i.e. domain-independent) engine to run the simulation.

As a consequence, all the entities in the virtual store are in fact represented by agents. Therefore, every entity in the store (items, information signs, the checkout, etc.) is likely to play an active role in the simulation, offering an original implementation of the affordances concept [1]. Each agent will consider every interaction in

P. Mathieu, D. Panzoli and S. Picault

Université Lille 1, Computer Science Dept. LIFL (UMR CNRS 8022)

e-mail: firstname.surname@univ-lillel.fr

1 The Format-STORE project is supported by the French ministry of Economy, Finances and Industry under the "2009 Serious Game" scheme. In-game images are the property of Idées-3Com. The authors are grateful to Jean-Baptiste Leroy for his committed involvement in the project.

2 http: //www.idees-3com. com

${ }^{3}$ http: //www.enaco.fr 
decreasing priority until one is deemed realisable (e.g. the preconditions are met and the limit distance is matched). While shopping in the store, every customer seems to follow a plan. Yet, every action is independent from the following and their sequence has merely been established by selecting priorities.

\begin{tabular}{|l||c|c|c|c|c|c|c|c|c|c|}
\hline Source/Target & $\emptyset$ & Employee & Customer & Door & Sign & Checkout & Item & Queue & Stain & Crate \\
\hline \hline \multirow{2}{*}{ Employee } & $\begin{array}{c}\text { Converse(0) } \\
\text { Move(0) }\end{array}$ & & $\begin{array}{c}\text { StartConversation(1,0) } \\
\text { EndConversation(1,0) }\end{array}$ & & & & $\begin{array}{c}\text { Remove(1,0) } \\
\text { Supply(1,0) } \\
\text { Order(1,0) }\end{array}$ & & Clean(1,0) & PutAway(1,0) \\
\hline Customer & $\begin{array}{c}\text { Wander(0) } \\
\text { GoTowards(1) } \\
\text { Converse(13) }\end{array}$ & Wait(2,3) & & Exit(1,12) & & Pay(2,10) & Get(2,5) & $\begin{array}{c}\text { StepIn(5,7) } \\
\text { MoveOn(1,8) } \\
\text { WalkOut(1,11) }\end{array}$ & & \\
\hline Door & SpawnCustomer(1) & & Acknowledge(10,0) & & & & & & & \\
\hline Sign & & & Acknowledge(10,0) & & & & & & & \\
\hline Checkout & & & $\begin{array}{c}\text { Acknowledge(10,0) } \\
\text { CheckOut(2,0) }\end{array}$ & & & & & & & \\
\hline Item & $\begin{array}{c}\text { Expire(1) } \\
\text { MakeStain(1) }\end{array}$ & & $\begin{array}{c}\text { Acknowledge(10,0) } \\
\text { Upset(1,0) } \\
\text { Ack_OutOfStock(1,0) }\end{array}$ & & & & & & & \\
\hline Queue & & & & & & & & & & \\
\hline Stain & & & Upset(1,0) & & & & & & & \\
\hline Crate & & & Upset(1,0) & & & & & & & \\
\hline
\end{tabular}

Fig. 1 The interaction matrix lists the interactions between each agent family. For instance: (Upset, 1, 0) at line "Stain" and column "Customer" means that a Stain agent can perform the "Upset" interaction on a Customer agent, with priority level 1 and at distance 0 (i.e. when the customer is very close to the stain).

\section{Demonstration}

\section{Game overview}

FORMAT-STORE is a single-player game where the player controls a salesperson in a virtual convenience store populated with intelligent customers shopping for goods (fig. 2.a) or conversing with the player (fig. 2.b).

During a session (20 min.), the game manager, which controls the simulation, invokes new customers in the store. Each customer is assigned a profile, a shopping list (see section 2) and possibly a question. Once invoked, a customer is an entirely autonomous agent, shopping for the items on its shopping list, conversing with the player and decreasing its own satisfaction level when encountering inconveniences (out of stock items, stains in the floor, crates obstructing the aisle). Finally, when exiting from the store, the customer is destroyed by the game manager. On this occasion, its satisfaction level is collected, so that the player is evaluated with flexibility by the virtual customers themselves. 


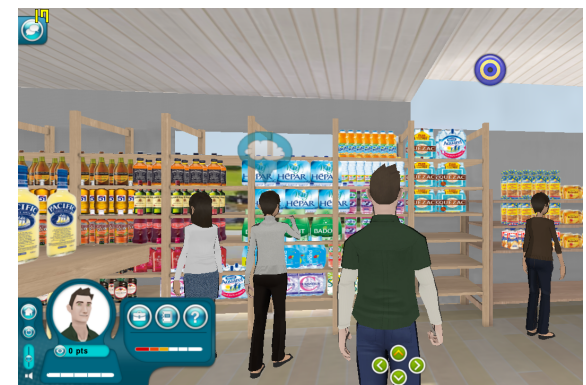

(a)

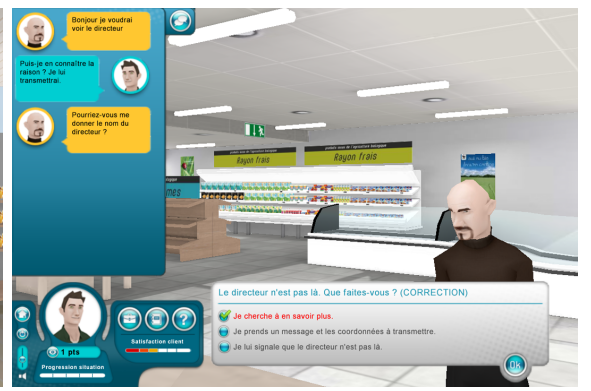

(b)

Fig. 2 (a) In FORMAT-STORE, the player controls an avatar in the virtual store using the keyboard arrows and interacts with the items and the customers using the mouse. (b) Dialogues in the game describe problematised situations and are rendered by means of a specific interface.

Mise en scène and dialogues

From a game perspective, IODA also facilitates the mise en scène of the simulation. In essence, several interactions can be forethought as a sequence by adjusting the preconditions. For example, when an item is taken by a customer, it can be damaged. The item is therefore likely to make a stain on the floor, that the employee must clean before other customers are upset by the stain. At the checkout, the behaviour of a customer is staged by four interactions, three of which (StepIn, MoveOn and WalkOut) are triggered by the checkout itself - e.g. the customer plays a passive role, being guided, moved and positioned by the checkout.

Another type of mise en scène involves designing more complex interactions like the dialogues in FORMAT-STORE, taking advantage of IODA's modularity. Dialogues extracted from problem situations defined by business experts from ENACO are contextualised in the game. Within the Converse interaction, they are interactively played in a specific interface when the player meets a virtual customer.

\section{Realistic customers}

In addition to the intrinsic variety offered by according visual models (fig. 2.a), customers profiles based on expert knowledge also define behavioural characteristics such as the size of the shopping list or the mood of the customer. IODA offers a mean to take them into account without impeding on the generic nature of the interactions, namely owing to a local interpretation of the primitives inside each agent. As a consequence, i) the impact will be different following the nature of the upsetting agent and; ii) the impact will be different following the mood of the Customer defined in the profile.

Variety is also obtained owing to the adaptive nature of the behaviours resulting from IODA's action selection mechanism. For instance, the allocation of pseudorandomly generated shopping lists to each customer entering the virtual store guar- 
antees that each customer takes a different path from each other. This is illustrated in figure 3. Besides the varied items, a path is made unique by the way customers read the information signs throughout the store to orient themselves. Although the navigation is guided by the signs, their encounterance reciprocally depends on the path taken, which turns the navigation into a highly complex and dynamic mechanism. Ultimately, the importance of the information signs can be highlighted by their removal from the environment, which causes the customers to wander aimlessly in the store, stumbling occasionally across an item in their shopping list.

Fig. 3 Recording and drawing the position of each customer during the simulation illustrates how varied routes are obtained owing to the mere attribution of different shopping lists, however relying on IODA's adaptive planning of each customer's behaviour.

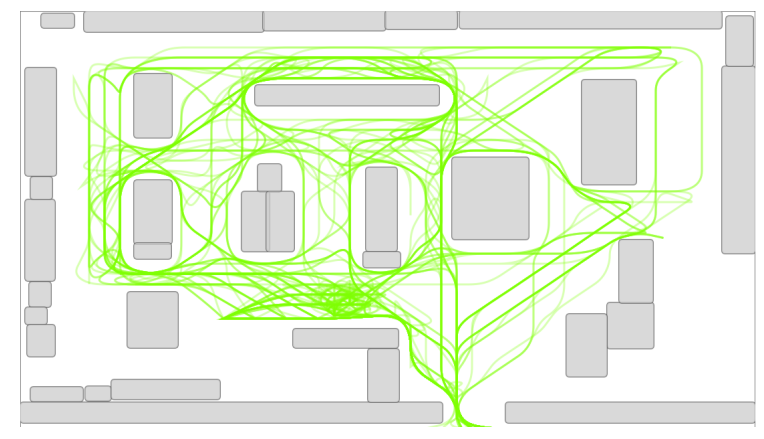

Finally, the behavioural differentiation is also expressed by the adaptivity of the virtual customers towards the unpredictable behaviour of the player controlling the employee. The player is integrated in the game by means of controlling one of the agents in the simulation, following a "letterbox" principle: actions from the player are captured, sent and expressed by the agent triggering the corresponding interaction. Conversely, interactions undergone by the agent are notified to the player. As a result, actions from the player are seamlessly conveyed in the simulation, preserving the autonomy of the agents and the independence of the action selection mechanism. On the other hand, the controlled agent introduces perturbations which, combined to the behavioural adaptivity of the customers, fosters a great variety on the situations presented to the player.

\section{References}

1. Gibson, J.J.: The Ecological Approach to Visual Perception. Hillsdale ; New Jersey ; London (1979)

2. Kubera, Y., Mathieu, P., Picault, S.: IODA: an interaction-oriented approach for multi-agent based simulations. Journal of Autonomous Agents and Multi-Agent Systems pp. 1-41

3. Mathieu, P., Panzoli, D., Picault, S.: Virtual customers in an agent world. In: Y. Demazeau, et al. (eds.) Proceedings of the 10th International Conference on Practical Applications of Agents and Multi-Agent Systems (PAAMS'12), Advances in Soft Computing. Springer (2012) 